\title{
A prática docente Guarani Mbya - liderança, engajamento e luta ${ }^{1}$
}

\author{
La práctica docente Guarani Mbya - liderazgo, compromiso y lucha \\ The guarani mbya teaching practice: leadership, engagement and fight
}

\author{
Janaína Aline dos Santos e Souza²
}

\begin{abstract}
Resumo
O presente trabalho apresenta as considerações finais da dissertação de mestrado "A prática docente Guarani Mbya - liderança, engajamento e luta", que trata sobre como as professoras e professores indígenas guarani mbya entendem sua prática docente. Parte do pressuposto de que a educação escolar indígena começa a ser ressignificada a partir de 1990, quando o Estado reconhece e dá maior respaldo às demandas dos movimentos e organizações indígenas. Assim, reestrutura-se uma instituição tipicamente não-indígena, norteada até então por princípios de catequização, civilização, integração e preservação. Ao se reconstruir junto aos projetos de futuro de cada etnia, a escola indígena se constitui como inovação educacional. A pesquisa de campo verificou qual a visão que docentes indígenas têm de suas práticas, considerando a hipótese de que estas se centram no modo de transmissão dos saberes tradicionais de sua cultura ou na mera reprodução do modelo de ensino escolar predominante, originalmente não-indígena, ainda que se trate oficialmente de uma escola diferenciada. $\mathrm{O}$ foco das observações centrou-se na Escola Estadual Indígena Guarani Gwyra Pepo, situada na aldeia Tenonde Porã, em Parelheiros, capital de São Paulo. Foram feitas entrevistas com as professoras e professores guarani. As informações recolhidas foram analisadas com bases teóricas das pesquisas antropológicas sobre a etnia Guarani e sociológicas sobre inovação educacional, bem como pelo recurso às produções da etnologia ameríndia sobre educação escolar indígena. Conclui-se que a prática docente das professoras e professores guarani é entendida como forma de luta, favorecida pelos espaços de discussão sobre educação escolar indígena e pela própria atuação como liderança. É vista tanto como valorização do nhandereko quanto como subsídio para compreender e enfrentar a sociedade não-indígena dominante, sendo modelo de engajamento e luta para reconceituação da educação pública de modo geral.
\end{abstract}

Palavras-Chave: Educação escolar indígena; Inovação educacional; Guarani Mbya; Prática docente.

\section{Resumen}

El presente trabajo presenta las consideraciones finales de la disertación de maestría "La práctica docente Guaraní Mbya - liderazgo, compromiso y lucha", que trata sobre cómo las profesoras y profesores indígenas guaraní mbya entienden su práctica docente. Parte del supuesto de que la educación escolar indígena comienza a ser resignificada a partir de 1990, cuando el Estado reconoce y da mayor respaldo a las demandas de los movimientos y organizaciones indígenas. Así, se reestructuró una institución típicamente no indígena, orientada hasta entonces por principios de catequización, civilización, integración y preservación. Al reconstruirse junto a los proyectos de futuro de cada etnia, la escuela indígena se constituye como innovación educativa. La investigación de campo verificó cuál es la visión que los docentes indígenas tienen de sus prácticas, considerando las hipótesis de que éstas se centran en el modo de transmisión de los saberes tradicionales de su cultura o en la mera reproducción del modelo de enseñanza escolar predominante, originalmente no indígena, aunque se trate oficialmente de una escuela diferenciada. El foco de las observaciones se centró en la Escuela Estadual Indígena Guaraní Gwyra Pepo, situada en la aldea Tenonde Porã, en Parelheiros, capital de São Paulo.

\footnotetext{
1 Artigo apresentado no II Seminário Latino-Americano de Estudos em Cultura - SEMLACult em Foz do Iguaçu/PR, Brasil, 2018.

2 Mestra em Sociologia da Educação; Universidade de São Paulo - USP; São Paulo, São Paulo, Brasil; janaina.souza@usp.br.
} 
Se realizaron entrevistas con las profesoras y profesores guaraní. Las informaciones recogidas fueron analizadas con bases teóricas de las investigaciones antropológicas sobre la etnia guaraní y sociológicas sobre innovación educativa, así como por el recurso a las producciones de la etnología amerindia sobre educación escolar indígena. Se concluye que la práctica docente de las profesoras y profesores guaraní es entendida como forma de lucha, favorecida por los espacios de discusión sobre educación escolar indígena y por la propia actuación como liderazgo. Es vista tanto como valorización del nhandereko como como subsidio para comprender y enfrentar la sociedad no indígena dominante, siendo modelo de compromiso y lucha para la reconceptualización de la educación pública de modo general.

Palabras claves: Educación escolar indígena; Innovación educativa; Guaraní Mbya; Práctica docente.

\begin{abstract}
This work presents the final considerations of the masters dissertation "The Guarani Mbya teaching practice: leadership, engagement and fight", which deals with how Guaraní Mbya indigenous teachers and teachers understand their teaching practice. It starts from the assumption that indigenous school education begins to be resignified after 1990, when the State recognizes and gives greater support to the demands of indigenous movements and organizations. Thus, a typically non-indigenous institution restructured itself, guided until then by principles of catechesis, civilization, integration and preservation. While the future ethnic projects are rebuilt with each ethnicity, the indigenous school constitutes an educational innovation. The field research verified how indigenous teachers view their practices, considering the hypothesis that these focus on the way of transmitting the traditional knowledge of their culture or on the mere reproduction of the predominantly non-indigenous school teaching model, although it is officially a differentiated school. The focus of the observations centered on the Guarani Gwyra Pepo State Indigenous School, located in the village Tenonde Porã, in Parelheiros, capital of São Paulo. Interviews were conducted with Guarani teachers. The collected information was analyzed with theoretical bases of the anthropological research on the Guarani ethnic group and sociological ones on educational innovation, as well as by the productions of Amerindian ethnology on indigenous school education. It is concluded that the teaching practice of Guaraní teachers is understood as a form of fight, favored by the spaces of discussion about indigenous school education and by the very act as leadership. It is seen both as valorization of the nhandereko and as a subsidy to understand and confront the dominant non-indigenous society, being a model of engagement and struggle for the reconceptualization of public education in general.
\end{abstract}

Keywords: Indigenous school education; educational innovation; Guarani Mbya; teaching practice.

\title{
1. Contextualização - pesquisa e pressupostos
}

Em meados de 2010, interessada pela questão indígena, engajei-me numa das propostas da disciplina de Política e Organização de Educação Básica no Brasil, no curso de licenciatura da Faculdade de Educação da Universidade de São Paulo, entre as quais, propunha o estudo de educação escolar indígena. Foi nesse tempo que conheci as comunidades indígenas Krukutu e Tenonde Porã, no extremo sul do município de São Paulo, no bairro Barragem, em Parelheiros.

Ambas as aldeias, pertencentes ao povo Guarani Mbya, possuíam (e possuem) escolas públicas estaduais em seus territórios, regidas pela legislação nacional (desde a Constituição Federal de 1988, perpassando pelas Leis de Diretrizes e Bases da Educação Nacional de 1996, até o Referencial Curricular Nacional para Escolas Indígenas de 1998) que fundamenta a Educação Escolar Indígena, garantindo uma educação escolar específica, diferenciada, intercultural e bilíngue. 
Quando conheci as comunidades, as duas principais impressões foram de que as terras indígenas garantiam a sobrevivência e manutenção de alguns aspectos culturais, bem como que a escola, mesmo sendo uma intrusa, provinda da cultura jurua (não guarani), poderia ser ressignificada. Nesse sentido, a escola se apresentaria diferenciada frente à escola não indígena, tanto por suas características específicas: étnicas, culturais e linguísticas, quanto por suas reformulações legais e contextuais - atendidas pelas legislações vigentes sobre educação escolar indígena e as singularidades da forma com que cada povo ou comunidade indígena educa suas crianças e jovens.

Por esta perspectiva, as escolas indígenas são, conforme Tassinari (2001, p. 50), espaços de fronteira, de "articulação e troca de conhecimentos, assim como espaços de incompreensões e de redefinições identitárias dos grupos envolvidos nesse processo, índios e não índios". Sendo lugares de encontros e de conflito entre dois mundos, entre dois saberes, o ocidental, não indígena, e o dos indígenas, também são inovadoras, como defende Abbonizio (2013), ao serem consideradas, hoje, como instrumento de luta, tendo sido outrora símbolos de aculturação e integração.

Partindo desses pressupostos, além das minhas observações de campo ao longo da licenciatura e de minhas experiências como professora, interessei-me pela visão que os professores e professoras indígenas têm de suas práticas, fundamentando-as no modo de transmissão dos saberes tradicionais de sua cultura, que estariam inscritas na luta por reconhecimento e seriam adaptadas à atividade escolar. Ou, apenas reproduzindo um modelo de ensino escolar predominante, originalmente não indígena, ainda que estivessem em um contexto oficial de escola diferenciada.

Supondo que a prática docente é norteada pelos princípios e engajamentos dos professores e professoras e que as decisões pedagógicas influenciam e mobilizam alunos e alunas, quais aspectos contribuiriam para o fortalecimento e valorização da própria cultura? Quais estratégias seriam usadas para que a escola se tornasse diferenciada? Como a prática docente poderia ser estratégia de luta por reconhecimento? Qual o papel desta prática frente às ressignificações da escola?

Visando identificar o caráter dessa educação, ao lado das variadas percepções possíveis entre não-indígenas, ganhava relevância responder à pergunta: como as professoras e professores indígenas Guarani Mbya entendem sua prática docente?

Para além de uma avaliação do que seja a educação escolar indígena ressignificada a partir das mobilizações dos movimentos e organizações indígenas, bem como das legislações que as favoreceram e favorecem sua autonomia, mesmo com os conflitos para sua efetivação, 
o estudo sobre como o próprio professorado indígena entende ser sua prática docente possibilita a compreensão dessa nova estrutura que se constitui, sendo caracterizada por sua inovação educacional.

Entendida aqui, a partir dos conceitos de Elie Ghanem $(2013,2016)$, pelo seu caráter diferenciado em relação a práticas costumeiras em determinado lugar e determinado grupo social, acontecendo na base dos sistemas escolares, caracterizada pela sua variedade e localização. Deste modo, a educação escolar indígena ao se confrontar com a educação escolar convencional não indígena, tenta superar seu caráter colonialista.

Para tanto, os objetivos específicos da pesquisa foram a obtenção de uma descrição do próprio corpo docente da escola sobre suas práticas docentes e o esclarecimento dos sentidos que os integrantes do corpo docente atribuem às práticas descritas. Centrando-me numa pesquisa etnográfica, a fim de melhor entender, interpretar os significados atribuídos àquilo que vejo no trabalho de campo, bem como, em entrevistas, baseadas nas premissas da história oral, como método para recolher as impressões dos professores e professoras indígenas sobre sua prática docente, também recorri a mobilização de uma série de leituras com o intuito de ampliar a visão sobre o contexto observado.

\section{Aprofundamentos e considerações}

Assim, lancei-me ao campo em busca de conhecer como as professoras e professores indígenas Guarani Mbya entendem sua prática docente. Para isso, considerei que a educação escolar indígena começou a ser ressignificada a partir de 1990, quando o Estado reconheceu e deu maior respaldo às demandas dos movimentos e organizações indígenas. Nesse momento, a escola, instituição tipicamente não-indígena, norteada até então por princípios de catequização, civilização, integração e preservação, começava a ser ressignificada, reconstruindo-se junto aos projetos de futuro de cada etnia e, assim, constituindo-se como inovação educacional.

Por meio das observações do cotidiano escolar da Escola Estadual Indígena Guarani Gwyra Pepo, a pesquisa se ateve às hipóteses de que aquele grupo docente vê a prática de seu ofício centrada no modo de transmissão dos saberes tradicionais de sua cultura ou na mera reprodução do modelo de ensino escolar predominante não-indígena, ainda que se tratasse oficialmente de uma escola diferenciada.

Para preencher as lacunas e dar voz às pessoas com quem me relacionei ao longo da pesquisa (professoras e professores indígenas, lideranças), fiz entrevistas colhendo depoimentos que descrevessem o que cada professora e professor indígena entendia da sua 
prática docente, bem como relatassem um pouco de sua trajetória para se tornar professora ou professor e as relações dessa atuação com se tornar ou ser liderança, que se apresentou um assunto relevante em todo o trabalho de campo.

Enveredei-me num percurso de leituras antropológicas sobre o povo Guarani a fim de melhor depreender as singularidades do povo que eu pretendia estudar, principalmente no que se relacionava à forma de produção, transmissão e aquisição de saberes, fundamentada nas obras de Testa $(2007 ; 2008)$, no intuito de relacioná-la à prática docente. Do mesmo modo, aprofundei-me nas produções da etnologia ameríndia sobre educação escolar indígena para compreensão do que é a escola indígena e como ela se insere na luta dos movimentos e organizações indígenas como reivindicação, ou em que momento supera seu caráter colonialista e busca se ressignificar a partir dos projetos de futuro da própria comunidade.

Concomitantemente, as pesquisas sociológicas sobre inovação educacional apontavam aspectos inovadores nesse processo de ressignificação da escola indígena frente aos modelos escolares convencionais, que seriam mais bem explanados por Abbonizio (2013) e Santos (2017). Fundamentos necessários para confrontar com as observações de campo e o olhar das professoras e professores indígenas, que, por sua vez, ocupam um lugar de intersecção entre sua própria cultura e a de jurua, sendo o elo entre o nhandereko (modo de ser, agir e viver guarani) e a escola.

A partir de 2010, umas das únicas professoras Guarani com formação em nível superior, Jera, liderança conceituada entre seu povo e os não indígenas, iniciou um movimento para tornar a Escola Gwyra Pepo uma escola diferenciada, pois, para além das definições legais de "escola específica, diferenciada, intercultural e bilíngue", a prática condizia com outra realidade, não apenas pela presença majoritária de professoras e professores não-indígenas, também pela ideia de uma escola que forneceria conhecimento de jurua e possibilitaria “tornar-se alguém”.

A ideia que se propalava em grande parte da comunidade coincidia com uma visão capitalista e individual, que via a escola como um lugar para alcançar desejos e sonhos pessoais, privilegiando um único tipo de saber, no caso, o dos jurua. No entanto, isso se confrontava com um princípio básico do nhandereko: as pessoas Guarani já são alguém quando nascem, sua vinda é uma concessão de Nhanderu e, por isso, cada "pessoinha" vem com uma missão. Além disso, considerar que quem não foi à escola não é alguém anularia a gama de conhecimento das xejaryi e xeramoĩ kuery (mulheres e homens mais velhos) da aldeia, cujos saberes não estão contidos em livros, mas, nas suas experiências e histórias. 


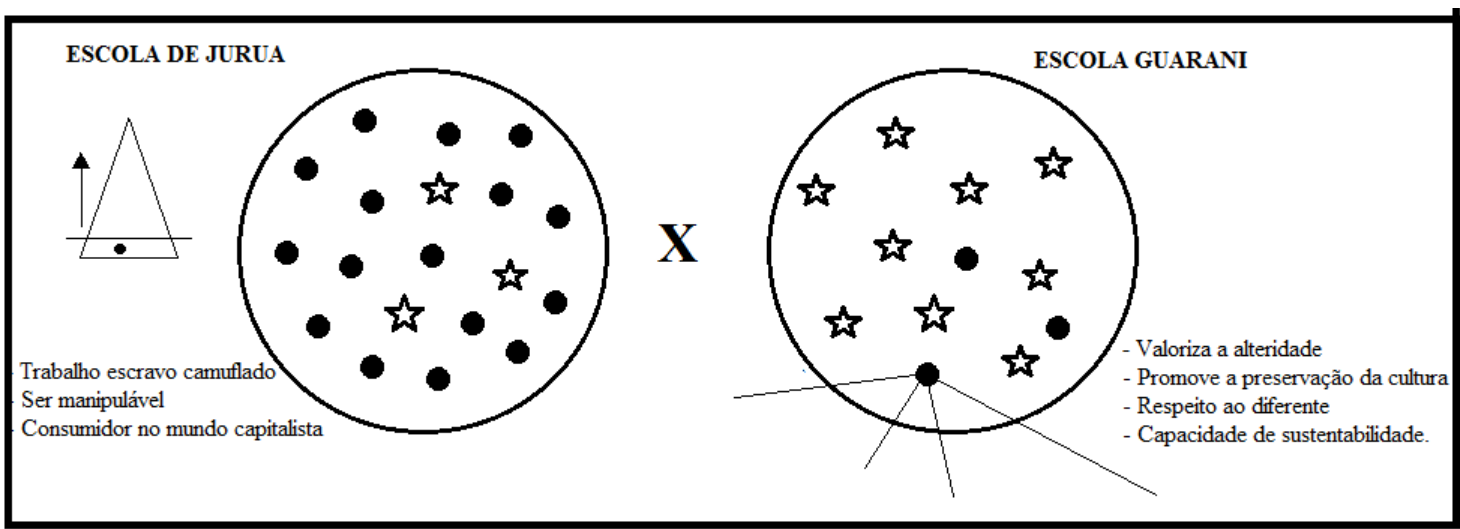

Sendo assim, era necessário refletir sobre os impactos da escola indígena dentro da aldeia, que começava a ocupar um lugar que não fazia parte da cultura guarani.

Não era possível excluir a escola de dentro da aldeia por ser uma demanda da comunidade e uma maneira de dominar alguns conhecimentos jurua, que não deixam de ser imprescindíveis, tanto pelo contato com a sociedade dominante quanto para reivindicação dos próprios direitos indígenas. Mas a escola também passou a servir de base alimentícia para muitas famílias. Era necessário reconstruí-la e torná-la efetivamente diferenciada, apelando para um discurso de que as professoras e professores, indígenas e não-indígenas, também deveriam ser diferenciadas e diferenciados do padrão escolar não-indígena.

No que tange aos padrões escolares indígenas e não-indígenas, é interessante o esquema que Jera expõe sobre o sistema escolar jurua e Guarani, no qual ela contrapõe o quanto a escola de jurua busca a padronização de seus alunos e alunas e os condiciona para um trabalho escravo camuflado, fazendo que sejam sujeitos manipuláveis e consumidores no mundo capitalista. Para ela, a escola de jurua, não se importaria com qualquer diferença apresentada por alunas e/ou alunos, concentrando-se apenas em inculcar o desejo de ascensão social e conquistas meritocráticas.

Em contrapartida, a escola Guarani, conforme Jera, preocupa-se com a alteridade, considerando que todas suas alunas e alunos detém de luz própria, respeitando a diferença e oportunizando que aqueles que não se enquadrem no sistema Guarani tenham o direito de escolher outros caminhos. Além disso, a escola indígena também forneceria elementos que auxiliariam na preservação da cultura, bem como, fundamentaria a capacidade de sustentabilidade e respeito ao meio ambiente.

Figura 1- Escola Jurua x Escola Guarani. Fonte: Elaborada pela autora.

Dessa maneira, pode ser entendido, a partir desse diagrama, baseado numa ilustração de Jera para defender sua tese, que na escola de juruakuery (plural de jurua), alunas e alunos são vistos de modo uniforme, sendo representados por pontinhos pretos, que apenas são 
preparados para entrada no mercado de trabalho, sem questionarem o sistema, sendo manipulados a quererem ser melhor um dos que os outros, intelectualmente e economicamente, para conquista de objetos de consumo.

Estando na base de uma pirâmide social hierárquica e classista, a escola não-indígena apenas reforçaria essa disputa determinada pelo sistema capitalista, em que os sonhos são meros produtos de consumo e o mundo do trabalho nada mais é que uma escravização camuflada, uma vez que não há saída dos processos de produção desenfreados e de seu consumo desenfreado e alimentado a todo instante pela própria escola e mídia.

Enquanto isso, as estrelinhas, seriam aquelas poucas alunas e alunos que se tornam singulares dentro desse sistema, que veem o mundo com outras perspectivas, e por vezes, lutam contra isso. Todavia, não saem do sistema que estão inseridos. Já na escola de nhandekuery (dos indígenas), alunas e alunos indígenas guarani, são respeitados por suas diferenças, sendo vistos como únicos, todas e todos, ainda que alguns se encantem com o universo não-indígena e queiram vivê-lo. Dessa maneira, ainda que a base da escola indígena guarani seja a manutenção de sua cultura, ainda que não se pretenda escolarizá-la, ela fornece subsídios para dialogar e sobreviver no sistema não indígena, não impedindo sua saída para outras vivências.

Por este viés, a escola indígena Guarani seria inovadora diante das práticas costumeiras da escola não-indígena convencional, da escola de jurua, uma vez que valoriza a alteridade, respeita o diferente e favorece o protagonismo de suas alunas e alunos, enquanto a escola não-indígena enxerga suas alunas e alunos de modo homogêneo, modelando-os para o mercado de trabalho e incentivando-os a competirem entre si para ascensão econômica.

Enquanto isso, a escola indígena guarani além de valorizar o contexto de sua comunidade escolar, de valorizar e fortalecer a própria cultura (nhandereko), promove formas de sustentabilidade, seja através da criação de projetos seja nos subsídios alimentares promovidos por ela. Além disso, não desconsidera a singularidade de cada aluna e aluno (estrelinhas) e entende os diferentes interesses que podem nortear cada um, de modo que também possibilita que elas e eles tenham habilidades e competências para viver em outros sistemas, que não o deles.

Aliás, é interessante que maior parte das professoras e professores guarani não estudaram além do ensino médio, "numa dinâmica bem segmentada, de forma bem tradicional e que saíram do terceiro do ensino médio sem saber escrever em guarani e sem ter tido aulas voltadas para questão de fortalecimento cultural ou dentro de um aprendizado de forma mais ampla" (Jera, 2017). No entanto, o processo de reestruturação da escola indígena, as 
diferentes estratégias de Jera para promover o fortalecimento do nhandereko e de reconstituir o lugar da escola dentro da aldeia despertaram a reflexão e contribuíam para formação que não tiveram.

\begin{abstract}
Então, eu comecei a atuar na equipe de liderança quando eu comecei a trabalhar na escola mesmo. A partir da escola que eu fui entendendo as coisas também, antes eu não sabia o que estava acontecendo na própria aldeia, daí a escola, abriu muito as portas pra mim, pra eu conhecer. Tanto que eu estou na equipe de liderança agora, a partir da escola também. Porque pra mim antes... tá, eu sou uma moradora aqui da aldeia, só isso e pronto. Não sabia o que ia além disso, o que estava acontecendo na minha própria aldeia. Daí, foi através da escola que eu fui aprendendo, tipo, ver as coisas, né. Daí, agora, tanto que eu estou até agora, tipo, na equipe de liderança. (Priscila, professora e liderança Guarani, 2017).
\end{abstract}

As jovens professoras e professores guarani entraram na escola como solução para as dificuldades de contato com docentes não-indígenas, uma vez que dominar sua própria língua facilitaria o ensino de outra cultura para as alunas e alunos falantes dessa mesma língua. Não tinham preocupação pedagógica de também ensinar a cultura jurua e guarani, mas, engajaram-se ao longo da sua trajetória docente. Dessa forma, a prática docente se constituiria de quatro etapas: o primeiro contato com a sala de aula e as dificuldades inerentes, que foram sendo superadas com o auxílio das professoras e professores mais experientes; o cotidiano e empirismo que promoviam autonomia para construção dos próprios planos de aula e consciência do papel docente vinculado aos projetos de futuro da comunidade; a prática docente que se consolidava com engajamento político; e que se completava com o tornar-se liderança.

Ser professora ou professor indígena, de modo geral, estabelece um lugar de referência para as demais pessoas da comunidade, além do fato de atuar para essa mesma comunidade da qual fazem parte, para quem lecionam e se relacionam fora do espaço escolar. Ainda que possam afirmar que não são docentes, mas, "estão docentes", porque não é um cargo efetivo e porque há mobilidade para atuarem em qualquer outro segmento dentro da aldeia, não é possível desvincular a atuação na sala de aula daquela fora da escola, o que exige um olhar ampliado sobre a comunidade e a compreensão de suas demandas.

A prática docente engaja as professoras e professores indígenas e o papel de liderança reforça esse engajamento. Fornece subsídios para luta, seja por uma educação escolar indígena realmente diferenciada seja por demarcação de terras, por saneamento básico, por serviços de saúde e qualquer outro problema ou necessidade da comunidade e do povo Guarani.

O engajamento, entendido como a compreensão do contexto político e socioeconômico da comunidade e das relações com a sociedade não-indígena, influencia na 
ressignificação da escola que se constrói com uma série de aspectos de inovação, por se diferenciar das práticas costumeiras não apenas das escolas convencionais, mas também, possivelmente, de outras escolas indígenas.

Primeiro, devido a posição não central do espaço escolar, a fuga do confinamento espacial com o favorecimento dos processos de ensino e aprendizagem em outros ambientes fora da escola, como a opy (casa de reza), as casas das xejaryi e xeramoĩ, a represa, o açude, as trilhas. Segundo, por causa da valorização dos saberes tradicionais e consequente fortalecimento do nhandereko, sob a precaução de não o escolarizar. E, terceiro, confluindo com a valorização do nhandereko, a preocupação com as condições atuais das pessoas da comunidade, que sobrevivem a partir dos projetos de sustentabilidade e agricultura familiar idealizados pelas professoras e professores indígenas, lideranças, com subsídios governamentais.

Por estes atributos, a prática docente das professoras e professores indígenas Guarani Mbya é entendida como forma de luta, favorecida pelos espaços de discussão sobre educação escolar indígena e pela própria atuação como liderança. É vista tanto como valorização do nhandereko quanto como subsídio para compreender e enfrentar a sociedade não-indígena dominante. Para além disso, mesmo sem saber, propõe novas frentes para a reconceituação da educação pública de modo geral.

\section{Referências}

ABBONIZIO, A. C. O. Educação escolar indígena como inovação educacional: a escola e as aspirações de futuro das comunidades. São Paulo, 2013. 193 p. Tese (Doutorado) Faculdade de Educação da Universidade de São Paulo. São Paulo, 2013.

BRASIL. MINISTÉRIO DA EDUCAÇÃO. Referenciais para a formação de professores. Brasília: MEC, 2002.

GHANEM, E. As inovações da escola Tuyuka: superando a educação colonialista. Relatório Científico. São Paulo, 2016.

Inovação em escolas públicas de nível básico: o caso redes da maré (Rio de Janeiro, RJ). Educação e Sociedade, Campinas, v. 34, n. 123, p. 425-440, abr/jun. 2013.

SANTOS, D. L. dos. Inovação educacional entre os Guarani Mbya da aldeia Tenonde Porã. São Paulo, 2017. 191 p. Dissertação (Mestrado) - Faculdade de Educação da Universidade de TASSINARI, A. M. I. A educação indígena: novos horizontes teóricos, novas fronteiras de educação. In: SILVA, A. L., FERREIRA, M. K. L. Antropologia, história e educação: a questão indígena e a escola. São Paulo: Global, 2001. 
TESTA, A. Q. Palavra, sentido e memória: educação e escola nas lembranças dos Guarani Mbya. 2007. 213f. Dissertação (Mestrado em Educação) - Faculdade de Educação Universidade de São Paulo. São Paulo, 2007.

. Caminhos de saberes guarani mbya: modos de criar, crescer e comunicar. 2014. 308

p. Tese (Doutorado em Antropologia Social). Faculdade de Filosofia, Letras e Ciências Humanas - Universidade de São Paulo. São Paulo, 2014. 